Check for updates

Cite this: RSC Adv., 2017, 7, 24122

Received 1st April 2017

Accepted 25th April 2017

DOI: $10.1039 / \mathrm{c} 7 \mathrm{ra03770h}$

rsc.li/rsc-advances

\section{Branched alkylphosphinic and disubstituted phosphinic and phosphonic acids: effective synthesis based on $\alpha$-olefin dimers and applications in lanthanide extraction and separation $\uparrow$}

\author{
I. E. Nifant'ev, (D) ${ }^{\star a b}$ M. E. Minyaev, ${ }^{\text {b }}$ A. N. Tavtorkin, ${ }^{\text {b }}$ A. A. Vinogradov ${ }^{b}$ \\ and P. V. Ivchenko ${ }^{a}$
}

A number of mono-alkylphosphinic acids $\mathrm{RCH}_{2} \mathrm{CH}_{2} \mathrm{CH}(\mathrm{R}) \mathrm{CH}_{2} \mathrm{P}(\mathrm{O})(\mathrm{H}) \mathrm{OH}$ 8-12 were obtained via interaction of $\alpha$-olefin vinylidene dimers $\mathrm{RCH}_{2} \mathrm{CH}_{2} \mathrm{C}(\mathrm{R})=\mathrm{CH}_{2}$ 3-7 ( $\mathrm{R}=n$-butyl, 3, 8; isobutyl, 4, 9; n-octyl, 5, 10; isopropyl, 6, 11; cyclohexyl, 7, 12) with $\mathrm{H}_{3} \mathrm{PO}_{2}$ in an isopropanol medium at $90{ }^{\circ} \mathrm{C}$. Hydrophosphinylation of 3 by 8 or $\mathrm{PhPO}_{2} \mathrm{H}_{2}$ at $140{ }^{\circ} \mathrm{C}$ resulted in disubstituted acids 13 and 14 . Alkylmethylphosphinic acids 15-19 and functionalized alkylphosphinic acids 20-22 have been synthesized via interaction of silyl ethers of mono-alkylphosphinic acids 8-12 with Mel, (2-chloromethyl)pyridine, acrylic acid or acrylamide. Non-catalytic hydroalumination of 3 with subsequent interaction with $\mathrm{PCl}_{3}$ and oxidation with $\mathrm{SO}_{2} \mathrm{Cl}_{2}$ led to the phosphonic acid anhydride, which was further used to obtain alkylphosphonic acids 23 and 24. It has been found that phosphinic acids 8-12 surpass di(2-ethylhexyl) phosphoric acid (extractant P204) in non-selective $\mathrm{Ln}^{3+}$ extractability ( $\mathrm{Ln}=\mathrm{La}, \mathrm{Pr}, \mathrm{Nd}$, Dy and Lu). Significantly higher selectivity for heavy lanthanide extraction ( $L n=D y, L u$ ), compared to that of $P 204$, is achieved by using a minimal excess of disubstituted phosphinic acids 13-24. Acid 13, which contains two branched substituents, demonstrated unique selectivity in the extraction of Lu in the presence of the other lanthanides. Dialkylphosphinic acids 16-18 and alkylarylphosphinic acid 14 possess a significant potential for the Pr/Nd pair separation. Taking into account the availability of 8-24 and the structural variability of the initial $\alpha$-olefin dimers $3-7$, the newly obtained compounds represent a promising group of rare-earth element extractants.

\section{Introduction}

Rare-earth elements (REEs) are widely used in the production of permanent magnets, lamp phosphors, NiMH batteries, ${ }^{\mathbf{1}}$ in the preparation of effective and irreplaceable catalysts for hydrocracking, diene polymerization ${ }^{2}$ and in other industrial processes. The extraction and separation of REEs, therefore, is a relevant technical issue., ${ }^{3,4}$ Various extraction methods have been productively used for a long time for this purpose. ${ }^{\mathbf{1 , 5 - 8}}$ By now, a great number of compounds have been studied as possible extractants of REEs. ${ }^{6,7} \mathrm{Di}$ (2-ethylhexyl) phosphoric acid (extractant P204, HDEHP or D2EHPA, Scheme 1) is still being used as the primary extractant in industry. However, the main drawbacks of this readily available compound are a low adjacent

${ }^{a}$ M. V. Lomonosov Moscow State University, Department of Chemistry, Moscow, Russian Federation. E-mail: inif@org.chem.msu.ru

${ }^{b}$ A. V. Topchiev Institute of Petrochemical Synthesis, Russian Academy of Sciences, Moscow, Russian Federation

$\dagger$ Electronic supplementary information (ESI) available: Synthetic and extraction experimental details, product characteristics, spectral data and NMR spectra. See DOI: $10.1039 / \mathrm{c} 7 \mathrm{ra} 03770 \mathrm{~h}$ separation factor, relatively low acidity for REE stripping, as well as low hydrolytic stability. Phosphonic and phosphinic acids are more hydrolytically stable and effective extractants when

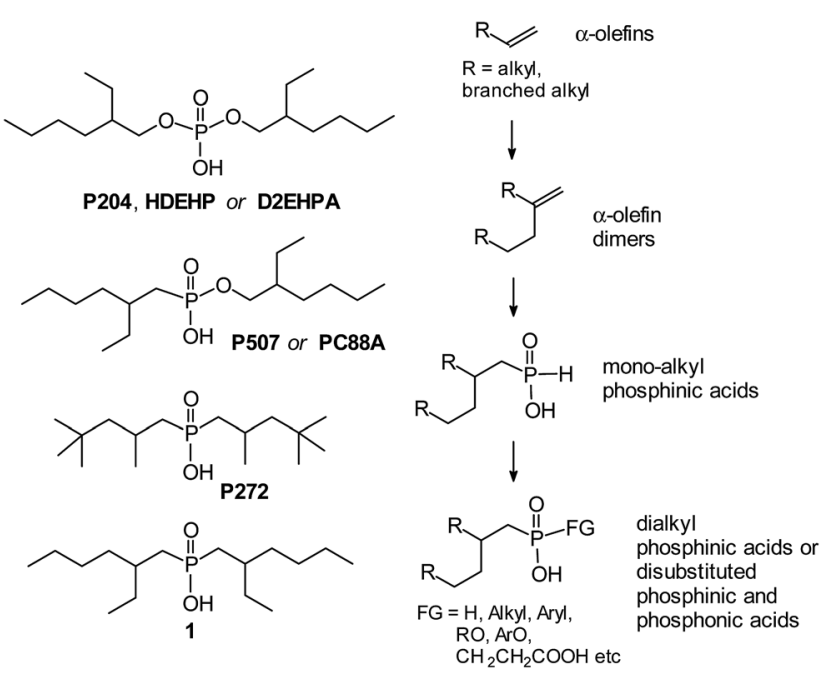

Scheme 1 Currently used and prospective REE extractants. 
compared with P204. Among these compounds are mono-2ethylhexyl ester of 2-ethylhexyphosphonic acid (P507 or $P C 88 A)$ and bis(2,4,4-trimethylpentyl) phosphinic acid (P272, Scheme 1), which have also been commercialized., ${ }^{\mathbf{1 , 6}}$ The properties of alkylphosphinic and phosphonic acids R-P(O)(OH)-FG depend on the structure of alkyl substituent R. It has been recently shown that acid $\mathbf{1}$ which contains $\beta$-branched alkyl fragment (Scheme 1), shows the maximum extraction efficiency among isomeric dioctylphosphinic acids. ${ }^{9}$

Recently ${ }^{\mathbf{1 0}, 11}$ we have developed an effective and general method of $\alpha$-olefin dimerization, which allows to selectively synthesize vinylidene dimers $\mathrm{RCH}_{2} \mathrm{CH}_{2} \mathrm{C}(\mathrm{R})=\mathrm{CH}_{2}$ containing a linear or branched alkyl $\mathrm{R}$ group in high yields. We proposed that a hydrophosphinilation reaction of these compounds can be carried out under controlled conditions with a formation of $\beta$-branched mono-alkyl phosphinic acids, which could be used to produce a whole family of new extractants with regulated lipophilicity, namely non-symmetrical disubstituted phosphinic and phosphonic acids (Scheme 1).

The current work is aimed at developing synthetic approaches to mono-alkylphosphinic and disubstituted phosphonic acids prepared from $\alpha$-olefin dimers $\mathrm{RCH}_{2} \mathrm{CH}_{2} \mathrm{C}(\mathrm{R})=$ $\mathrm{CH}_{2}$, as well as the study of the REE extraction efficiency of the newly-obtained compounds.

\section{Experimental}

\section{Materials and methods}

All of the synthetic experiments were conducted under an argon atmosphere. Solvents used in synthetic procedures were distilled, stored under argon, and degassed under reduced pressure with stirring in the reaction vessels prior to adding reagents (for details on reagent and solvent preparation, see the $\mathrm{ESI}_{\dagger}^{\dagger}$ ). $\mathrm{CDCl}_{3}$ (Cambridge Isotope Laboratories, Inc., D 99.8\%) was used as purchased. The ${ }^{1} \mathrm{H}$ and ${ }^{13} \mathrm{C}$ NMR spectra were recorded on a Bruker AVANCE 400 spectrometer $(400 \mathrm{MHz})$ at $20{ }^{\circ} \mathrm{C}$. The chemical shifts are reported in ppm relative to the solvent residual peaks. Elemental analysis (C, H) was performed on a Perkin Elmer Series II CHNS/O Analyser 2400. pH values of the aqueous phase were measured with a digital $\mathrm{pH}$ meter calibrated daily with 4.01 and 7.00 standard buffer solutions. The concentration of rare earth ions in the water phase was determined by inductively coupled plasma atomic emission spectroscopy (ICP-AES) with the Agilent 7500c G 3155B instrument after proper dilution. When determined concentrations of lanthanides in water phase were very low, the ICP-AES analyses were repeated without dilution.

\section{Synthetic procedures}

\section{$\alpha$-Olefin dimerization}

General procedure. Triisobutylaluminium solution (1 M TIBA in hexane, $5 \mathrm{~mL}, 5 \mathrm{mmol})$ and $\left[\mathrm{O}\left(\mathrm{SiMe}_{2} \mathrm{Cp}\right)_{2}\right] \mathrm{ZrCl}_{2}(106 \mathrm{mg}, 0.25$ $\mathrm{mmol})$ were added at $60{ }^{\circ} \mathrm{C}$ to liquid monomer $(1 \mathrm{~mol})$. After $20 \mathrm{~min}$ of stirring, $\mathrm{Et}_{2} \mathrm{AlCl}$ ( $1 \mathrm{M}$ in hexane, $0.5 \mathrm{~mL}, 0.25 \mathrm{mmol}$ ) and MMAO-12 (1.05 $\mathrm{M}$ in toluene, $2.4 \mathrm{~mL}, 2.5 \mathrm{mmol})$ were added. After 6-8 h of stirring, the mixture was cooled to room temperature, $5 \mathrm{~mL}$ of methanol and $2 \mathrm{~mL}$ of water were added. After 10 min of stirring, $\mathrm{Na}_{2} \mathrm{SO}_{4}(5 \mathrm{~g})$ was added and the mixture was stirred for an additional $10 \mathrm{~min}$. After that, the mixture was filtered through a layer of silica and distilled under reduced pressure. Product yields and characteristics, including ${ }^{1} \mathrm{H}$ and ${ }^{13} \mathrm{C}$ NMR spectra, elemental analysis and GC data, are given in the ESI. $\dagger$

Hydrophosphorylation of $\alpha$-olefin dimers: preparation of 8-12

General procedure. A mixture of $\alpha$-olefin dimer 3-7 (66 mmol), $50 \%$ aq. $\mathrm{H}_{3} \mathrm{PO}_{2}(14.5 \mathrm{~mL}, 264 \mathrm{mmol})$ and i-PrOH $(80 \mathrm{~mL})$ was degassed under reduced pressure, filled with argon and heated to $90{ }^{\circ} \mathrm{C}$. AIBN was added with vigorous stirring in 7 portions by $100 \mathrm{mg}$ at $30 \mathrm{~min}$ intervals. The mixture was cooled to room temperature and diluted by pentane $(100 \mathrm{~mL})$. The organic layer was washed by water $(3 \times 100 \mathrm{~mL})$, dried over $\mathrm{Na}_{2} \mathrm{SO}_{4}$ and evaporated. The residue was purified by gradient column chromatography (silica 60-200, por. 40) using a $\mathrm{CH}_{2} \mathrm{Cl}_{2}-\mathrm{MeOH}$ mixture (from 100:1 to $1: 1$ by volume). Product yields and characteristics, including ${ }^{1} \mathrm{H}$ and ${ }^{13} \mathrm{C}$ NMR spectra, elemental analysis and GC data, are given in ESI. $\dagger$

\section{Functionalization of mono-alkylphosphinic acids}

Methyl(alkyl)phosphinic acids 15-19, general procedure. The mixture of mono-alkylphosphinic acid $(20 \mathrm{mmol}), \mathrm{Me}_{3} \mathrm{SiCl}$ (5.43 g, $50 \mathrm{mmol})$ and $\mathrm{CH}_{2} \mathrm{Cl}_{2}(20 \mathrm{~mL})$ was cooled to $0{ }^{\circ} \mathrm{C}$. Triethylamine $(5.06 \mathrm{~g}, 50 \mathrm{mmol})$ was added to the mixture, which was then allowed to warm up to room temperature and was stirred for $2 \mathrm{~h}$. After that, the mixture was cooled to $0{ }^{\circ} \mathrm{C}$ and methyl iodide $(5.75 \mathrm{~g}, 50 \mathrm{mmol})$ was added. After $16 \mathrm{~h}$ at room temperature, the mixture was diluted by pentane $(30 \mathrm{~mL})$. Organic layer was washed by water $(3 \times 100 \mathrm{~mL})$, dried over $\mathrm{Na}_{2} \mathrm{SO}_{4}$ and evaporated. The residue was purified by gradient column chromatography (silica 60-200, por. 40) using $\mathrm{CH}_{2} \mathrm{Cl}_{2}-$ $\mathrm{MeOH}$ mixture (from $100: 1$ to $1: 1$ by volume). Product yields and characteristics, including ${ }^{1} \mathrm{H}$ and ${ }^{13} \mathrm{C}$ NMR spectra, are given in ESI. $\dagger$ Synthetic protocols and spectral data for compounds 13, 14, 20-24 are in the ESI. $\dagger$

\section{Extraction experiments}

The lanthanide mixture solutions were prepared from $\mathrm{LnCl}_{3}$ solutions of determined concentrations, $\mathrm{NaCl}$ and $\mathrm{HCl}$. The initial lanthanide mixture solutions contained $2.00 \times 10^{-3} \mathrm{M}$ of each lanthanide $\left(\mathrm{Ln}=\mathrm{La}, \mathrm{Pr}, \mathrm{Nd}, \mathrm{Dy}, \mathrm{Lu} ;[\mathrm{Ln}]_{0}=0.01 \mathrm{M}\right)$ and $1.00 \mathrm{M} \mathrm{NaCl}$ to keep ionic strength of the water phase at $1 \mathrm{M}$ and possessed $\mathrm{pH}=2.00$ or 3.00 . Extractants (HL) were dissolved in decane to reach the required concentration $(0.200 \mathrm{M}, 0.142 \mathrm{M}$ or $0.0667 \mathrm{M}$ ). All extraction experiments were carried out at room temperature with a water to organic phase ratio of $1: 1$ (by volume). Two phases were vigorously stirred for 12 hours. The

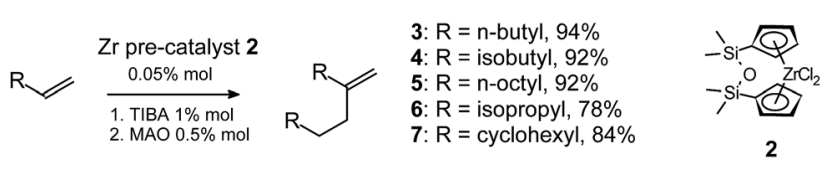

Scheme 2 Synthesis of alpha-olefin dimers 3-7. 
equilibrium $\mathrm{pH}$ and the lanthanide concentration in the water phase were measured after phase separation by gravity settling.

Distribution ratio $(D)$, extraction efficiency $(E)$, separation factor $\left(\beta_{\mathrm{Ln} 1 / \mathrm{Ln} 2}\right)$, and extraction equilibrium constant $\left(K_{\mathrm{ex}}\right)$ were calculated in the usual manner (see ESI $\dagger$ ).

\section{Results and discussion}

\section{Synthesis of alkylphosphinic and alkylphosphonic acids}

Compounds 3-7 were obtained via selective catalytic dimerization of $\alpha$-olefins using our recently developed procedure using the zirconocene pre-catalyst 2 (Scheme 2) activated by TIBA and MAO. ${ }^{10,11}$ Compounds 3-5 and 7 are isomerically pure vinylidene olefins. Hydrocarbon 6 contains insignificant amounts $(\sim 2 \%)$ of reduction product (for experimental details and product characterization, see the ESI $\dagger$ ).

Vinylidene dimers of olefins 3-7 are promising precursors for preparing functional derivatives with regulated lipophilicity. ${ }^{11-16}$ The idea of vinylidene olefin functionalization relies on the hydrophosphinilation reaction. This reaction is a general method of synthesis of phosphinic acids and their derivatives. ${ }^{17,18}$ Radical hydrophosphinilation initiated by peroxides ${ }^{19-21}$ or AIBN, $, 922,23$ needs high temperature and long reaction time. As a result, the product is usually a mixture that includes mono- and diphosphinic acids; the process has low regioselectivity. Catalytic hydrophosphinilation, ${ }^{11,24-26}$ is not very effective in the case of vinylidene olefins. A recently developed method of phosphinic acid synthesis relies on initiation by microwave irradiation. In the absence of a radical initiator, this method demonstrated low efficiency in the synthesis of mono-alkylphosphinic acids from vinylidene olefins. ${ }^{27}$ Starting from vinylidene olefins of various structures, a series of symmetric dialkylphosphinic acids, including compound 1, was obtained in the presence of AIBN. Mono-alkylphosphinic acids were synthesized only in moderate yields. ${ }^{9}$

We proposed that in the case of highly reactive vinylidene olefins 3-7 thermally initiated hydrophosphnilation with $\mathrm{H}_{3} \mathrm{PO}_{2}$ can be carried out in two steps: (1) synthesis of monoalkylphosphinic acids under relatively mild conditions, and (2) transformations of mono-alkylphosphinic acids into dialkylphosphinic acids under more rigorous conditions without MW-irradiation. The choice of the solvent is of fundamental importance in this case. It has been determined earlier ${ }^{22,23}$ that the presence of strong acids significantly accelerates radical hydrophosphinilation. This method has been effectively used in cases of terminal olefins. However, it is not effective for vinylidene dimers 3-5 due to a side cationic oligomerization reaction. We used a series of solvents (DMF, dioxane, DME, isopropanol) and determined that in the protonic solvent, ${ }^{\mathrm{i}} \mathrm{PrOH}$, hydrophosphinilation of $\mathbf{3}$ proceeds smoothly under mild conditions $\left(90{ }^{\circ} \mathrm{C}\right)$ and allows to obtain mono-alkylphosphinic acid 8 in $80 \%$ yield and high regioselectivity. For $\alpha$-olefin dimers $4-7$, a three hour reaction allowed us to obtain over $90 \%$ conversion of initial hydrocarbons and $80-90 \%$ isolated yields of branched alkyl phosphinic acids 9-12 (Scheme 3).

By using compound 3 , we also demonstrated the possibility of carrying out a hydrophosphinilation reaction in two steps. The acid 8, obtained under relatively mild conditions, was

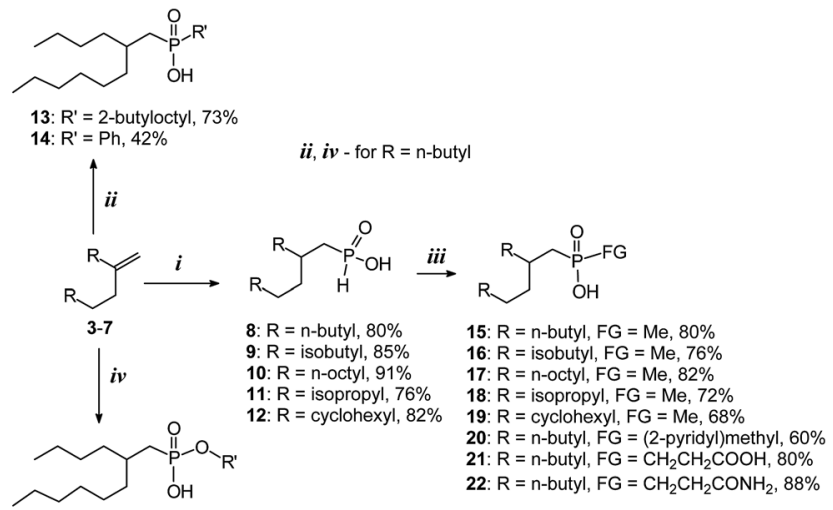

23: $\mathrm{R}^{\prime}=2$-ethylhexyl, $40 \%$

24: $R^{\prime}=2,6$-diisopropylphenyl, $55 \%$

Scheme 3 Synthesis of alkylphosphinic and disubstituted phosphonic acids. Regents and conditions: (i) 2 eq. $\mathrm{H}_{3} \mathrm{PO}_{2}$, i- $\mathrm{PrOH}, 90^{\circ} \mathrm{C} .3 \mathrm{~h}, \mathrm{AIBN}$ dropwise; (ii) 8 or $\mathrm{PhPO}_{3} \mathrm{H}, 145^{\circ} \mathrm{C} .5 \mathrm{~h}, \mathrm{AlBN}$ dropwise; (iii) (1) $\mathrm{TMSCl}$, $\mathrm{NEt}_{3}$ in $\mathrm{CH}_{2} \mathrm{Cl}_{2}, 2 \mathrm{~h}$; (2) RHal or $\mathrm{CH}_{2}=\mathrm{CHCOX}, 16 \mathrm{~h}$; (iv) (1) $\mathrm{TIBA}, 140^{\circ} \mathrm{C}$, 40 h; (2) $\mathrm{PCl}_{3}, 10$ eq.; (3) $\mathrm{SO}_{2} \mathrm{Cl}_{2}, 16$ h; (4) $\mathrm{R}^{\prime} \mathrm{OH}, \mathrm{NEt}_{3}$ or Py, $16 \mathrm{~h}$.

reacted with dimer 3 under substantially more harsh conditions at $145^{\circ} \mathrm{C}$ with addition of the initiator by small portions, which resulted in formation of dialkylphosphinic acid $\mathbf{1 3}$ (Scheme 3). The reaction was carried out with a high regioselectivity and satisfactory isolated yield. In contrast, interaction of $\mathbf{3}$ with phenylphosphinic acid proceeded with moderate regioselectivity. Product 14 was obtained with a yield of $42 \%$.

The newly obtained mono-alkylphoshinic acids 8-12 were used in the synthesis of asymmetrical phosphinic and phosphonic acids. We used a method developed earlier by Regan and coll. in order to introduce alkyl substitutes and functional groups. ${ }^{28-33}$ This method includes generation of silyl ethers through interaction of phosphinic acids with TMSCl in the presence of bases. The silyl ethers act as P-nucleophilic particles and promote alkylation or Michael addition in situ. We introduced mono-alkylphosphinic acids 8-12 into a reaction with TMSCl and methyl iodide, which produced a series of methyl(alkyl)phosphinic acids 15-19 in high yields. The interaction of 8 with 2-(methyl chloride)pyridine resulted in product 22 . The applicability of the Michael reaction was demonstrated in the case of interaction of $\mathbf{8}$ with acrylic acid and acrylamide, providing compounds 20 and 21, respectively (Scheme 3).

Ethers of alkylphosphinic acids $\mathbf{2 3}$ and $\mathbf{2 4}$ were obtained from 1-hexene dimer 3 through a multistage reaction. At the first stage, via interaction with triisobutylaluminium (TIBA), an organoaluminium derivative was obtained. This reaction is traditionally carried out in the presence of $\left(\eta^{5}-\mathrm{C}_{5} \mathrm{H}_{5}\right)_{2} \mathrm{ZrCl}_{2}$, however, in the case of $\mathbf{3}$, there is no need for a catalytic process to take place: an autooxidation test showed that 3 quantitatively transformed into tris(2-butyloctyl)aluminium after $40 \mathrm{~h}$ at $140{ }^{\circ} \mathrm{C}$. The reaction of the organoaluminium derivative with an excess of $\mathrm{PCl}_{3}$ led to compound $\mathrm{C}_{12} \mathrm{H}_{25} \mathrm{PCl}_{2}$ of $c a .75 \%$ purity. The latter, upon treatment with $\mathrm{SO}_{2} \mathrm{Cl}_{2}$, was reacted with 2-ethylhexanol or 2,6-diisopropylphenol. The products of these reactions were compounds 23 and $\mathbf{2 4}$, respectively (Scheme 3). 
All newly obtained compounds were purified by gradient column chromatography. Their structures and purity were confirmed by spectral methods and elemental analysis (see ESI $\dagger$ ) prior to studying them as lanthanide extractants.

\section{Lanthanide extraction}

Standard methods of extractability studies of organic compounds are based on determining the element concentrations in organic and aqueous phases after reaching equilibrium. According to published data, ${ }^{1,734,35}$ dialkylphosphoric, dialkylphosphinic and dialkylphosphonic acids exist in hydrocarbon media as dimers $(\mathrm{HL})_{2}$. The extraction equilibrium can be described by eqn (1). ${ }^{1,34-36}$

$$
\mathrm{Ln}^{3+}{ }_{(\mathrm{aq})}+3(\mathrm{HL})_{2(\mathrm{org})} \leftrightarrows\left[\mathrm{Ln}\left(\mathrm{HL}_{2}\right)_{3}\right]_{(\mathrm{org})}+3 \mathrm{H}^{+}{ }_{(\mathrm{aq})}
$$

A number of conventional parameters are used for a quantitative analysis of extractant properties: distribution ratio $(D)$, extraction efficiency $(E)$ and separation factor $(\beta)$ (See ESI $\dagger)^{6,7}$ The extraction equilibrium constant $\left(K_{\mathrm{ex}}\right)$ for each lanthanide can be represented by the eqn (2).

$$
K_{\text {ex }}=\frac{\left[\operatorname{Ln}\left(\mathrm{HL}_{2}\right)_{3}\right]_{\mathrm{org}}\left[\mathrm{H}^{+}\right]_{\mathrm{aq}}^{3}}{\left[\mathrm{Ln}^{3+}\right]_{\mathrm{aq}}\left[(\mathrm{HL})_{2}\right]_{\mathrm{org}}^{3}}
$$

Rare-earth elements extraction ability of the synthesized phosphinic and phosphonic acids was studied for $\mathrm{La}, \mathrm{Nd}$, Pr, Dy, and Lu. Di(2-ethylhexyl)phosphoric acid (P204) was used as a benchmark. All extraction experiments were carried out at initial concentration of each lanthanide in aqueous phase of $0.002 \mathrm{M}$ (with the total lanthanide concentration $[\mathrm{Ln}]_{0}=0.01 \mathrm{M}$ ) and at $[(\mathrm{Na}, \mathrm{H}) \mathrm{Cl}]=1 \mathrm{M}$ at equal volumes of organic and aqueous phases.

In order to determine the conditions that would reveal selectivity of the used extractants, two parameters were varied: initial $\mathrm{pH}$ of the aqueous phase and initial extractant concentration in organic phase $[\mathrm{HL}]_{0}$. First, we compared lanthanide extractability of mono-alkyl phosphinic acids 8, 10, and P204 at $[\mathrm{HL}]_{0}=0.200 \mathrm{M}$ and at initial $\mathrm{pH}=2.00$ and 3.00 . The extraction efficiency of $P 204$ was expectedly lower for lighter lanthanides at $\mathrm{pH}=2$. The acids $\mathbf{8}$ and $\mathbf{1 0}$ were more effective towards extraction of all lanthanides than $P 204$ regardless of initial $\mathrm{pH}$ of aqueous phase (Table 1: entries 1-4, 6, 8, see extraction efficiency), not demonstrating any selectivity toward heavier lanthanides. For example, the separation factor values $\beta_{\mathrm{Dy} / \mathrm{Nd}}$ for $P 204\left(\beta_{\mathrm{Dy} / \mathrm{Nd}}=225\right.$ and 262$)$ and compounds 8, $10\left(\beta_{\mathrm{Dy} / \mathrm{Nd}}=5.4-\right.$ 15.6) differ by more than an order of magnitude (for details, see ESI†).

Dependency of lanthanide extraction efficiency from $[\mathrm{HL}]_{0}$ was estimated at initial $\mathrm{pH}=3$ of the aqueous phase, using the more sterically crowded alkylphosphinic acid 8. Expectedly, lanthanide extractability did not change significantly at lowering the phosphinic acid concentration by $29 \%$. Selectivity toward heavier lanthanides (Dy, Lu) increases greatly upon further decrease of $[\mathrm{HL}]_{0}$ from $0.142 \mathrm{M}$ to $0.067 \mathrm{M}$ (Table 1, entries 9 and 10). This behavior correlates with eqn (1)

\begin{tabular}{|c|c|c|c|c|c|c|c|c|c|c|c|}
\hline Entry & & 1 & 2 & 3 & 4 & 5 & 6 & 7 & 8 & 9 & 10 \\
\hline Extractant & & P204 & 8 & 10 & P204 & $P 272^{a}$ & 8 & 8 & 10 & 10 & 10 \\
\hline$[\mathrm{HL}]_{0}$ & & 0.200 & 0.200 & 0.200 & 0.200 & 0.200 & 0.200 & 0.067 & 0.200 & 0.142 & 0.067 \\
\hline Initial pH & & 2.00 & 2.00 & 2.00 & 3.00 & 3.00 & 3.00 & 3.00 & 3.00 & 3.00 & 3.00 \\
\hline Final pH & & 1.39 & 1.40 & 1.46 & 1.48 & - & 1.51 & 1.50 & 1.54 & 1.54 & 1.56 \\
\hline \multirow{5}{*}{$\begin{array}{l}\text { Extraction } \\
\text { efficiency } E, \%\end{array}$} & $\mathrm{La}$ & 77.24 & 99.41 & 98.74 & 87.64 & 7.88 & 99.85 & 56.20 & 99.42 & 95.08 & 47.20 \\
\hline & Pr & 93.82 & 99.77 & 99.54 & 97.04 & 17.46 & 99.94 & 80.95 & 99.80 & 98.40 & 74.80 \\
\hline & $\mathrm{Nd}$ & 95.08 & 99.76 & 99.54 & 97.65 & 19.24 & 99.94 & 81.15 & 99.80 & 98.46 & 75.38 \\
\hline & Dy & 99.98 & 99.97 & 99.97 & 99.99 & 65.64 & 99.99 & 99.81 & 99.98 & 99.95 & 99.18 \\
\hline & $\mathrm{Lu}$ & 100.00 & 100.00 & 100.00 & 100.00 & 97.67 & 100.00 & 100.00 & 100.00 & 100.00 & 99.99 \\
\hline \multirow{5}{*}{$\begin{array}{l}\text { Distribution } \\
\text { ratio } D\end{array}$} & $\mathrm{La}$ & 3.39 & 168.0 & 78.4 & 7.09 & 0.086 & 675.0 & 1.28 & 173.0 & 19.3 & 0.894 \\
\hline & Pr & 15.2 & 438.0 & 218.0 & 32.8 & 0.212 & 1670 & 4.25 & 489.0 & 61.5 & 2.97 \\
\hline & $\mathrm{Nd}$ & 19.3 & 418.0 & 217.0 & 41.6 & 0.238 & 1620 & 4.31 & 490.0 & 64.0 & 3.06 \\
\hline & Dy & 4360 & 3810 & 3390 & 10900 & 1.91 & 8710 & 534.0 & 6100 & 2030 & 121.0 \\
\hline & $\mathrm{Lu}$ & 33500 & 167000 & 167000 & 479000 & 41.92 & 515000 & 112000 & 83700 & 360000 & 8370 \\
\hline \multirow{6}{*}{$\begin{array}{l}\text { Separation } \\
\text { factor } \beta\end{array}$} & $\mathrm{Pr} / \mathrm{La}$ & 4.48 & 2.61 & 2.79 & 4.62 & 2.47 & 2.47 & 3.31 & 2.83 & 3.18 & 3.32 \\
\hline & $\mathrm{Nd} / \mathrm{La}$ & 5.70 & 2.49 & 2.78 & 5.87 & 2.79 & 2.41 & 3.36 & 2.84 & 3.31 & 3.43 \\
\hline & $\mathrm{Nd} / \mathrm{Pr}$ & 1.27 & 1.05 & 1.00 & 1.27 & 1.13 & 1.03 & 1.01 & 1.00 & 1.04 & 1.03 \\
\hline & Dy/Nd & 225 & 9.11 & 15.6 & 262 & 8.02 & 5.37 & 124 & 12.5 & 31.8 & 39.5 \\
\hline & $\mathrm{Lu} / \mathrm{Nd}$ & $-^{b}$ & - & - & - & 176.0 & - & - & - & - & - \\
\hline & Lu/Dy & - & - & - & - & 21.9 & - & - & - & - & - \\
\hline \multirow{5}{*}{$\lg K_{\mathrm{ex}}$} & $\mathrm{La}$ & -0.21 & 1.49 & 0.98 & -0.14 & -6.02 & 1.76 & 1.86 & 1.08 & 0.87 & 1.42 \\
\hline & $\operatorname{Pr}$ & 0.44 & 1.90 & 1.42 & 0.52 & -4.94 & 2.16 & 2.38 & 1.53 & 1.38 & 1.94 \\
\hline & $\mathrm{Nd}$ & 0.54 & 1.89 & 1.42 & 0.62 & -4.86 & 2.14 & 2.38 & 1.53 & 1.39 & 1.96 \\
\hline & Dy & 2.90 & 2.84 & 2.61 & 3.04 & -2.46 & 2.87 & 4.48 & 2.63 & 2.89 & 3.55 \\
\hline & $\mathrm{Lu}$ & 3.78 & 4.49 & 4.31 & 4.69 & -0.82 & 4.65 & 6.80 & 3.77 & 5.14 & 5.39 \\
\hline
\end{tabular}

Table 1 Data for lanthanide extraction using $P 204,8$ and 10 at different $\mathrm{pH}$ and extractant concentrations ([Ln] $=0.01 \mathrm{M})$

${ }^{a}$ Published data. ${ }^{9}$ Distribution ratio and separation factors have been calculated based on extraction efficiency. $D=E\left(V_{\text {aq }} / V_{\text {org }}\right) /(1-E), V_{\text {aq }}=V_{\text {org }}$, $\beta_{\mathrm{Ln} 1 / \mathrm{Ln} 2}=D_{\mathrm{Ln} 1} / D_{\mathrm{Ln} 2} \cdot{ }^{b}$ Unreliable separation factor values have been omitted. 
Table 2 Data for lanthanide extraction using $P 204,8,10,13-24$. $[\mathrm{Ln}]_{0}=0.01 \mathrm{M}$, $[\mathrm{HL}]_{0}=0.067 \mathrm{M}$, initial $\mathrm{pH}=3.00$

\begin{tabular}{|c|c|c|c|c|c|c|c|c|c|c|c|c|c|c|c|c|}
\hline Extractant & & $P 204$ & 8 & 10 & 13 & 14 & 15 & 16 & 17 & 18 & 19 & 20 & 21 & 22 & 23 & 24 \\
\hline Final pH & & 1.54 & 1.50 & 1.56 & 2.01 & 1.52 & 1.80 & 1.54 & 1.58 & 1.51 & 1.53 & 1.61 & 1.61 & 2.66 & 1.73 & 2.56 \\
\hline \multirow{4}{*}{$\begin{array}{l}\text { Extraction } \\
\text { efficiency } E, \%\end{array}$} & $\mathrm{La}$ & 14.40 & 56.20 & 47.20 & 4.40 & 7.14 & 6.80 & 6.68 & 3.57 & 6.68 & 6.68 & 14.40 & 26.00 & 30.00 & 21.43 & 7.14 \\
\hline & $\operatorname{Pr}$ & 50.00 & 80.95 & 74.80 & 4.80 & 42.86 & 11.60 & 10.24 & 7.14 & 10.24 & 10.24 & 41.60 & 46.00 & 56.80 & 42.86 & 17.86 \\
\hline & Dy & 99.74 & 99.81 & 99.18 & 12.46 & 99.86 & 97.38 & 97.16 & 98.38 & 98.38 & 96.65 & 95.41 & 98.36 & 99.67 & 98.84 & 92.50 \\
\hline & $\mathrm{Lu}$ & 99.94 & 100.00 & 99.99 & 82.39 & 100.00 & 99.97 & 99.96 & 99.98 & 99.99 & 99.95 & 99.94 & 99.98 & 99.99 & 99.89 & 99.89 \\
\hline \multirow{3}{*}{$\begin{array}{l}\text { Distribution } \\
\text { ratio } D\end{array}$} & $\mathrm{La}$ & 0.168 & 1.28 & 0.894 & 0.046 & 0.077 & 0.073 & 0.072 & 0.037 & 0.072 & 0.072 & 0.168 & 0.351 & 0.429 & 0.273 & 0.077 \\
\hline & Dy & 380 & 534 & 121 & 0.142 & 695 & 37.1 & 34.2 & 60.5 & 60.5 & 28.8 & 20.8 & 60.0 & 304 & 85.5 & 12.3 \\
\hline & $\mathrm{Lu}$ & 1670 & 112000 & 8370 & 4.68 & 35000 & 3350 & 2260 & 5000 & 7390 & 2170 & 1670 & 5580 & 16700 & 945 & 874 \\
\hline \multirow{4}{*}{$\begin{array}{l}\text { Separation } \\
\text { factor } \beta\end{array}$} & $\mathrm{Pr} / \mathrm{La}$ & 5.94 & 3.31 & 3.32 & 1.10 & 9.75 & 1.80 & 1.59 & 2.08 & 1.59 & 1.59 & 4.23 & 2.42 & 3.07 & 2.75 & 2.83 \\
\hline & $\mathrm{Nd} / \mathrm{La}$ & 8.11 & 3.36 & 3.43 & 1.04 & 16.0 & 1.99 & 2.69 & 3.12 & 2.69 & 2.13 & 4.71 & 2.37 & 3.18 & 3.42 & 3.39 \\
\hline & $\mathrm{Nd} / \mathrm{Pr}$ & 1.36 & 1.01 & 1.03 & 1.14 & 1.64 & 1.11 & 1.69 & 1.50 & 1.69 & 1.34 & 1.11 & 1.03 & 1.04 & 1.24 & 1.20 \\
\hline & $\mathrm{Dy} / \mathrm{Nd}$ & 279 & 124 & 39.5 & 3.22 & 564 & 255 & 178 & 525 & 315 & 189 & 26.2 & 72.2 & 223 & 91.6 & 47.3 \\
\hline & $\mathrm{Nd}$ & 1.07 & 2.38 & 1.96 & -2.67 & 1.00 & -1.12 & -0.21 & -0.59 & -0.11 & -0.29 & -2.66 & 0.61 & 0.99 & 0.28 & -3.10 \\
\hline & Dy & 3.52 & 4.48 & 3.55 & -2.16 & 3.75 & 1.29 & 2.04 & 2.13 & 2.38 & 1.98 & -1.24 & 2.47 & 3.34 & 2.24 & -1.43 \\
\hline & $\mathrm{Lu}$ & 4.16 & 6.80 & 5.39 & -0.65 & 5.45 & 3.25 & 3.86 & 4.04 & 4.47 & 3.86 & 0.66 & 4.44 & 5.08 & 3.29 & 0.42 \\
\hline
\end{tabular}

${ }^{a}$ Unreliable separation factor values have been omitted.

describing the equilibrium of lanthanide complex formation the $\mathrm{Ln}^{3+}$ ion forms a complex with six molecules of alkylphosphite.

In order to compare extraction ability of newly obtained compounds, further experiments were carried out at $[\mathrm{HL}]_{0}$ of $0.067 \mathrm{M}$ (the ratio of $[\mathrm{HL}]_{0} /[\mathrm{Ln}]_{0}=1 / 6.7$ ), which provided $c a$. $11 \%$ molar excess of the extractant (see eqn (1)). Under these conditions, the extraction characteristics of $\mathbf{8}$ barely differed from those of 10. Both mono-alkylphosphinic acids demonstrated slightly worse selectivity towards late lanthanides (Dy, $\mathrm{Lu}$ ) in comparison with $P 204, \beta_{\mathrm{Dy} / \mathrm{Nd}}=124$ (8) 39.5 (10) and 279 (P204). Therefore, lanthanide extraction with compounds $\mathbf{9}, 11$ and 12, which are structurally similar to $\mathbf{8}$ and 10, has not been studied. Comparative experiments regarding extraction of $\mathrm{La}$,

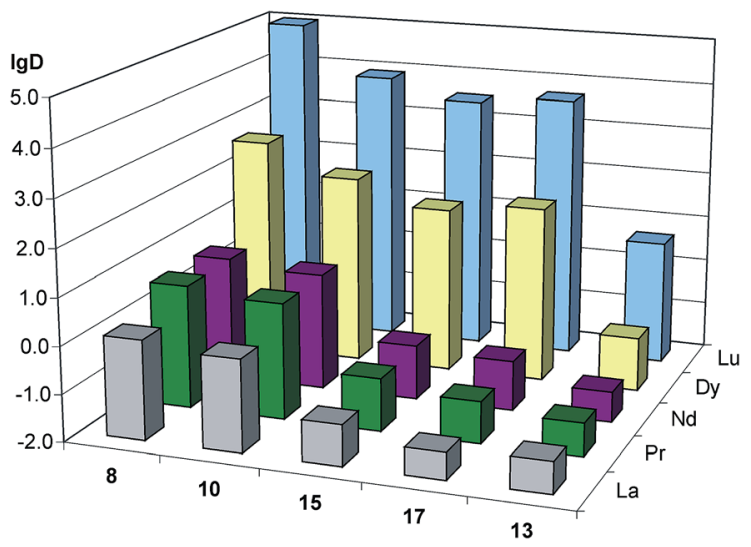

Fig. 1 The influence of the substitution of $\mathrm{H}$-atom $(8,10)$ with methyl $(15,17)$ and branched alkyl (13) group on $\lg D$ of alkylphosphinic acids.
$\mathrm{Nd}, \mathrm{Pr}, \mathrm{Dy}$, and $\mathrm{Lu}$ at $\mathrm{pH}=3$ and initial concentrations $[\mathrm{Ln}]_{0}=$ $0.01 \mathrm{M}$ and $[\mathrm{HL}]_{0}=0.067 \mathrm{M}$ were carried out for compounds 1324. The results are summarized in Table 2 .

As it has been noted while discussing preliminary experiments (Table 1), mono-alkylphosphinic acids $\mathbf{8}$ and $\mathbf{1 0}$ are effective non-selective extractants for all examined lanthanides, possessing significantly lower selectivity compared to even $P 204$. Substitution of the hydrogen atom $(\mathbf{8}, \mathbf{1 0})$ with a methyl group (15, 17), and further, by a 2-butyloctyl fragment (13), abruptly lowers the extraction efficiency (see ESI $\dagger$ ) and lowers $\lg D$ of all lighter lanthanides (La, Pr, Nd) (Fig. 1). This allows us to consider phosphinic acids containing branched alkyl and methyl substitutes as selective extractants of heavy lanthanides. The extraction properties of compounds 15-19 are similar to each other (Fig. 2). The substitution of $n$-alkyl fragment R (15, 17) with an isoalkyl one $(\mathbf{1 6}, \mathbf{1 8})$ leads to an increase in separation efficiency for $\mathrm{Nd} / \mathrm{Pr}$ pair. The best separation of light (La, $\mathrm{Nd}, \mathrm{Pr}$ ) and heavy (Dy, Lu) lanthanides is achieved with 17, containing a more bulky alkyl fragment based on a 1-decene dimer.

It should also be noted that the replacement of the methyl substituent with a $\beta$-branched alkyl fragment in compound $\mathbf{1 3}$ leads to a unique extraction selectivity for the Dy/Lu pair (Fig. 1). This selectivity makes $\mathbf{1 3}$ markedly different from compound $\mathbf{1}$ described earlier. ${ }^{9}$ This allows us to examine $\mathbf{1 3}$ as a promising selective extractant for $\mathrm{Lu}$ and heavier lanthanides from REE mixtures.

The extraction ability of functionalized di-substituted alkylphosphinic acids 20-22, phosphonic acid 23 and alkylarylphosphinic acid 14 is qualitatively close to that of P204 (Fig. 3). At the same time, the characteristics of extractant $\mathbf{2 4}$ are similar 


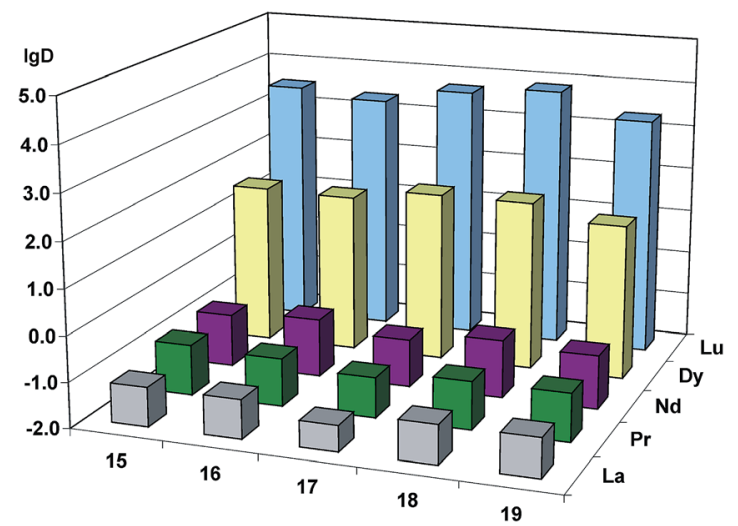

Fig. 2 The influence of the alkyl substituent structure in (methyl) phosphinic acids $15-19$ on $\lg D$.

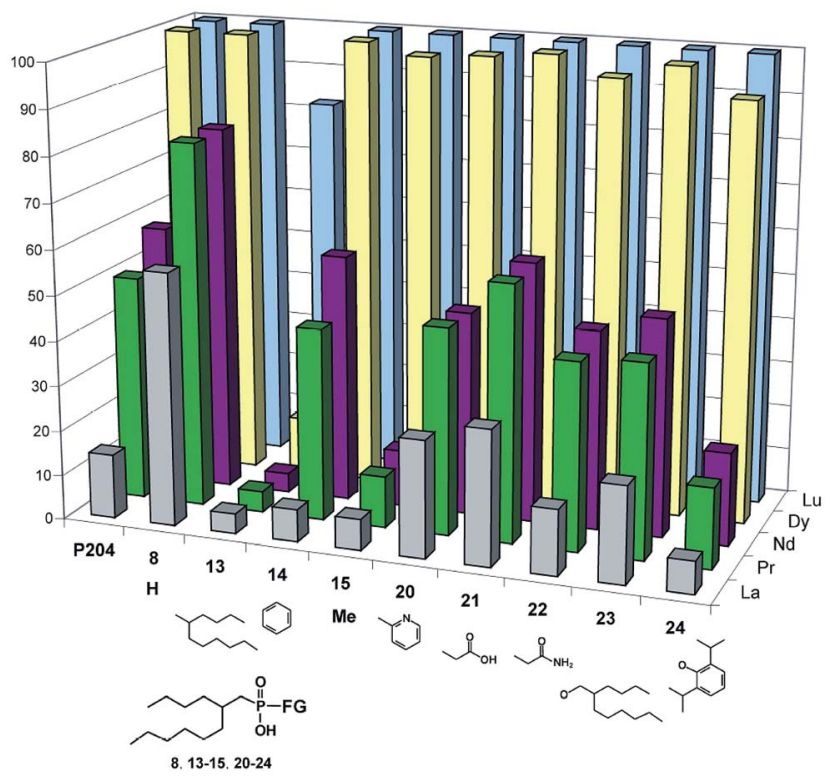

Fig. 3 The influence of second functional group substitute in phosphinic and phosphonic acids $\mathrm{C}_{12} \mathrm{H}_{25} \mathrm{P}(\mathrm{O})(\mathrm{OH})-\mathrm{FG}$ on their extractive properties.

to extraction properties of dialkylphosphinic acids 13 and 15-19 (see ESI $\dagger$ ). Somewhat higher ability to extract La for 20-22 compared to 13-19 might be attributed to the presence of additional $\sigma$-donor fragments, resulting in the chelating effect. The highest values $\beta_{\mathrm{Pr} / \mathrm{La}}=9.8$ and $\beta_{\mathrm{Nd} / \mathrm{La}}=16.0$ are demonstrated by compound 14. Separation selectivity for $\mathrm{Pr} / \mathrm{Nd}$ and La for $\mathbf{1 4}$ is higher than the selectivity of extractant $P 204\left(\beta_{\mathrm{Pr} / \mathrm{La}}=\right.$ $5.9, \beta_{\mathrm{Nd} / \mathrm{La}}=8.1$ ) and compound 23 , which is similar in structure to extractant $P 507$. The latter and $P 272$, at present moment, are among prospective extractants for separating La from a mixture of $\mathrm{La}, \mathrm{Pr}$, and $\mathrm{Nd}^{37}$

Special attention should be paid to the noticeable difference in extractability for two adjacent lanthanides ( $\mathrm{Pr}$ and $\mathrm{Nd}$ ) that was displayed by extractants $P 204,14,16-19,23$ and 24 (Table 2: $\left.\beta_{\mathrm{Nd} / \mathrm{Pr}}=1.20-1.69\right)$ within the chosen experimental conditions $\left([\mathrm{HL}]_{0}=0.067 \mathrm{M}\right)$. Extractant 14 demonstrated the maximum potential for separation of Pr from Nd due to higher extraction efficiency ( $42.9 \%$ for $\operatorname{Pr}$ and $55.2 \%$ for $\mathrm{Nd})$ at $\beta_{\mathrm{Nd} / \mathrm{Pr}}=1.64$. Furthermore, 14 possessed the highest value of $\beta_{\mathrm{Dy} / \mathrm{Nd}}=564$ among all studied acids.

Within the series of synthesized phosphinic acids, 14 represents a sole example of an entirely unexplored class of chemical compounds - (branched alkyl)(aryl)phosphinic acids. Our experiments have demonstrated that this extractant class deserves the closest attention and further studies.

By using eqn (2), we calculated the $\lg K_{\mathrm{ex}}$, which lie in the intervals of -3.6 to +1.9 for $\mathrm{La}$ and -0.6 to +6.8 for $\mathrm{Lu}$ (for diagram, see ESI $\dagger$ ). The values of $\lg K_{\text {ex }}$ for most compounds studied herein are higher by 3-6 orders of magnitude than those of dialkylphosphinic acids of the $\left(\mathrm{C}_{8} \mathrm{H}_{17}\right)_{2} \mathrm{POOH}$ type, ${ }^{9}$ which explains their high non-selective extraction ability at $[\mathrm{HL}]_{0}=0.2 \mathrm{M}$. Compound 13, $\left(\mathrm{C}_{12} \mathrm{H}_{25}\right)_{2} \mathrm{POOH}$, possessing the worst overall extraction ability, has $\lg K_{\mathrm{ex}}$ values that are similar to those published earlier for dioctylphosphinic acids. ${ }^{9}$ The previously published $\lg K_{\text {ex }}$ values for di-(2,3-dimethylbutyl)phosphinic acid are in good agreement with our data. ${ }^{38}$ With the exception of $\mathbf{2 0}$ and $\mathbf{2 4}$, there is a positive correlation between the $\lg K_{\text {ex }}$ values and the general extraction ability of the studied acids. For compounds 8, 10 and extractant P204, $\lg K_{\text {ex }}$ data that have been obtained at different initial values of $[\mathrm{HL}]_{0}$ and $\mathrm{pH}$ differ insignificantly. The differences can be explained by the fact that the equilibrium shown on eqn (1) does not take into account the formation of higher HL oligomers and other side reactions. However, as it has been shown earlier, ${ }^{1,9,39}$ these side reactions do not play a fundamental role in comparative studies of lanthanide extraction by organic compounds of the same type from aqueous solutions.

\section{Conclusions}

We have proposed herein an effective method of synthesis of branched alkylphosphinic and alkylphosphonic acids based on vinylidene dimers of $\alpha$-olefins. The synthetized phosphinic (822) and phosphonic $(\mathbf{2 3}, \mathbf{2 4})$ acids have demonstrated a high lanthanide extraction potential. It has been determined that:

- Monosubstituted phosphinic acids 8 and $\mathbf{1 0}$ possess a higher non-selective lanthanide extractability in comparison with industrial extractant $P 204$;

- The previously unknown alkylmethylphoshinic acids 15-19 are effective and selective extractants of heavy lanthanides (Dy, $\mathrm{Lu})$.

- Dialkylphosphinic acid 13, containing two bulky branched alkyl substituents and being formally similar in structure to the commercial extractant $P 272$ and to the described earlier dioctylphosphinic acids, ${ }^{9}$ demonstrates high selectivity for the "heavy" lanthanide separation within the pair Dy/Lu;

- Extractant 14, bearing phenyl and branched alkyl substituents, demonstrates a high potential for separation of "light" lanthanides from La and for lanthanide separation within the Pr/Nd pair. It significantly surpasses $P 204$ by both parameters.

Therefore, the newly synthesized phosphinic and phosphonic acids may be considered as promising extractants for the separation of rare-earth metals. New structural types of 
asymmetrical acids, especially (branched alkyl)(aryl)phosphinic acids that are derivatives of $\mathbf{1 4}$, are being considered for further research.

\section{Acknowledgements}

Financial support by the Russian Science Foundation (Grant No. 15-13-00053) is gratefully acknowledged.

\section{Notes and references}

1 F. Xie, T. A. Zhang, D. Dreisinger and F. Doyle, Miner. Eng., 2014, 56, 10-28.

2 Neodymium Based Ziegler Catalysts - Fundamental Chemistry, Advances in Polymer Science, ed. O. Nuyken, Springer International Publishers, 2006, vol. 204.

3 K. Binnemans, P. T. Jones, B. Blanpain, T. Van Gerven, Y. Yang, A. Walton and M. Buchert, J. Cleaner Prod., 2013, 51, 1-22.

4 Z. Sun, H. Cao, Y. Xiao, J. Sietsma, W. Jin, H. Agterhuis and Y. Yang, ACS Sustainable Chem. Eng., 2017, 5, 21-40.

5 H.-S. Yoon, C.-J. Kim, K.-W. Chung, S.-D. Kim, J.-Y. Lee and J. R. Kumar, Hydrometallurgy, 2016, 165, 27-43.

6 D. A. Atwood, Sustainable Inorganic Chemistry, Wiley, 2016.

7 Application of Ionic Liquids on Rare Earth Green Separation and Utilization, ed. J. Chen, Springer-Verlag, Berlin, Heidelberg, 2016.

8 Rare Metal Technology 2015, ed. N. R. Neelameggham, S. Alam, H. Oosterhof, A. Jha, D. Dreisinger and S. Wang, Springer International Publishers, 2016.

9 R.-B. Du, H. An, S. Zhang, D. Yu and J.-C. Xiao, RSC Adv., 2015, 5, 104258-104262.

10 I. E. Nifant'ev, A. A. Vinogradov, A. A. Vinogradov and P. V. Ivchenko, Catal. Commun., 2016, 79, 6-10.

11 I. Nifant'ev, P. Ivchenko, A. Tavtorkin, A. Vinogradov and A. Vinogradov, Pure Appl. Chem., 2017, DOI: 10.1515/pac2016-1131.

12 H. Sato and A. Shishikura, US Pat., 2008234152A1, 2008, Idemitsu Kosan.

13 H. Sato, T. Kashiwamura and Y. Ikeda, Eur. Pat., 1908746A1, 2008, Idemitsu Kosan.

14 H. Sato, T. Kashiwamura, T. Okamoto and K. Yokota, US Pat., 7402610B2, 2008, Idemitsu Kosan.

15 C. J. Kenneally and J. J. Scheibel, PCT Pat., WO2006050994A1, 2006, Procter\&Gamble.

16 P. Hofmann, DE Pat., 3121573A1, 1982.
17 C. Queffélec, M. Petit, P. Janvier, D. A. Knight and B. Bujoli, Chem. Rev., 2012, 112, 3777-3807.

18 C. S. Demmer, N. Krogsgaard-Larsen and L. Bunch, Chem. Rev., 2011, 111, 7981-8006.

19 P. Odorisio, S. M. Andrews, T. E. Thompson, S. Wu, P. Thanki, D. M. Rane, D. Joseph and J. Wang, US Pat., 8436131 (B2), 2013, BASF SE.

20 M. Martinez, C. Herranz, N. Mirallez and A. Sastre, J. Dispersion Sci. Technol., 1995, 16, 221-232.

21 D. F. Peppard, G. W. Mason and C. Andrejasich, J. Inorg. Nucl. Chem., 1966, 28, 2347-2359.

22 T. Pietzonka, R. Damon, M. Russell and S. Wattanasin, Bioorg. Med. Chem. Lett., 1996, 6, 1951-1954.

23 M. S. Markoulides and A. C. Regan, Org. Biomol. Chem., 2013, 11, 119-129.

24 S. Deprèle and J.-L. Montchamp, J. Am. Chem. Soc., 2002, 124, 9386-9387.

25 K. Bravo-Altamirano and J.-L. Montchamp, Tetrahedron Lett., 2007, 48, 5755-5759.

26 S. Deprèle and J.-L. Montchamp, Org. Lett., 2004, 6, 38053808.

27 P. Troupa, G. Katsiouleri and S. Vassiliou, Synlett, 2015, 26, 2714-2719.

28 E. A. Boyd, M. Corless, K. James and A. C. Regan, Tetrahedron Lett., 1990, 31, 2933-2936.

29 E. A. Boyd, A. C. Regan and K. James, Tetrahedron Lett., 1994, 35, 4223-4226.

30 Y. Yang and J. K. Coward, J. Org. Chem., 2007, 72, 5748-5758.

31 D. M. Bartley and J. K. Coward, J. Org. Chem., 2005, 70, 67576774.

32 J. Lauer-Fields, K. Brew, J. K. Whitehead, S. Li, R. P. Hammer and G. B. Fields, J. Am. Chem. Soc., 2007, 129, 10408-10417.

33 C. Fougère, E. Guénin, J. Hardouin and M. Lecouvey, Eur. J. Org. Chem., 2009, 6048-6054.

34 J. Zhang, B. Zhao and B. Schreiner, Separation Hydrometallurgy of Rare Earth Elements, Springer-Verlag, Berlin Heidelberg, 2016.

35 B. Ramachandra Reddy, S. Radhika and B. Nagaphani Kumar, Sep. Sci. Technol., 2010, 45, 1426-1432.

36 M. I. Saleh, M. F. Bari and B. Saad, Hydrometallurgy, 2002, 63, 75-84.

37 R. Banda, H. S. Jeon and M. S. Lee, Hydrometallurgy, 2012, 121-124, 74-80.

38 W. Junlian, C. Guang, X. Shengming, Y. Zhili and Z. Qin, J. Rare Earths, 2016, 34, 724-730.

39 B. Swain and E. O. Out, Sep. Purif. Technol., 2011, 83, 82-90. 